\title{
Pengaruh Beban Kerja, Kompensasi Dan Rotasi Kerja Terhadap Kepuasan Kerja Melalui Stres Kerja Pada Pt. Bank Sulteng Luwuk Banggai
}

\author{
Nurrahmi Utami Tamping ${ }^{1}$, Rita N.Taroreh ${ }^{2}$, Arrazi Hasan Jan ${ }^{2}$ \\ ${ }^{1}$ Mahasiswa Progam Studi Magister Manajemen Fakultas Ekonomi Dan Bisnis \\ ${ }^{2}$ Progam Studi Magister Manajemen Fakultas Ekonomi Dan Bisnis \\ Universitas Sam Ratulangi, Manado \\ Universitas Sam Ratulangi, Manado \\ Email : rahmiutamitamping@gmail.com
}

Received: 04 Januari 2021; Revised: 26 Februari 2021; Accepted: 28 April 2021

DOI: http://dx.doi.org/10.37905/aksara.7.2.619-632.2021

\begin{abstract}
Abstrak
Jenis penelitian ini adalah penelitian yang dilakukan dengan menggunakan metode analisis jalur untuk menjelaskan hubungan langsung dan tidak langsung terhadap beban kerja, kompensasi dan rotasi kerja melalui stres kerja. Objek penelitian yang dipilih adalah PT Bank Sulteng Luwuk Cabang Banggai dengan jumlah sampel sebanyak 34 responden dengan menggunakan teknik analisis sampel jenuh. Teknik analisis data dengan bantuan software SPSS v.22.0 for Windows.

Hasil penelitian menunjukkan bahwa beban kerja (X1) berpengaruh signifikan terhadap stres kerja karyawan (Y1). Kompensasi (X2) berpengaruh signifikan terhadap stres kerja karyawan (Y1). Rotasi kerja (X1) berpengaruh signifikan terhadap stres kerja karyawan (Y2). Beban kerja (X1) berpengaruh signifikan terhadap kepuasan kerja karyawan (Y2). Kompensasi (X2) berpengaruh signifikan terhadap kepuasan kerja karyawan (Y2). Rotasi Kerja (X3) berpengaruh signifikan terhadap kepuasan kerja karyawan (Y2). Stres kerja (Y1) berpengaruh signifikan terhadap kepuasan kerja karyawan (Y2).

Kata kunci: beban kerja, kompensasi, rotasi, stres kerja dan kepuasan kerja karyawan

Abstract

This type of research is a research conducted using the path analysis method to explain the direct and indirect relationship to workload, compensation and job rotation through work stress. The research object chosen was PT Bank Sulteng Luwuk, Banggai Branch with a total sample of 34 respondents using saturated sample analysis techniques. Data analysis techniques with the help of SPSS v.22.0 for Windows software.

The results showed that the workload (X1) had a significant effect on employee work stress (Y1). Compensation (X2) has a significant effect on employee job stress $(Y 1)$. Work rotation (X1) has a significant effect on employee job stress (Y2). Workload (X1) has a significant effect on employee job satisfaction (Y2). Compensation (X2) has a significant effect on employee job satisfaction (Y2). Job Rotation (X3) has a significant effect on employee job satisfaction (Y2). Job stress (Y1) has a significant effect on employee job satisfaction (Y2).
\end{abstract}


Keywords: workload, compensation, rotation, job stress and employee job satisfaction

\section{PENDAHULUAN}

Sesuai dengan visi menjadi bank daerah terpercaya di Indonesia, memahami kebutuhan nasabah, memberikan solusi keuangan yang tepat, membangun kemitraan yang saling menguntungkan dan berkelanjutan. PT. Bank Sulawesi Tengah Cabang Luwuk Banggai terus berupaya mengembangkan dan meningkatkan kinerja pegawai yang tidak lepas dari dukungan sumber daya manusia yang berkualitas. Suatu perusahaan dalam menjalankan aktivitasnya akan berusaha untuk mencapai tujuan yang telah ditetapkan. Satu hal yang harus diperhatikan bersama adalah keberhasilan berbagai kegiatan dalam perusahaan dalam mencapai tujuannya, tidak hanya bergantung pada keunggulan teknologi, dana operasional yang tersedia, sarana atau prasarana yang dimiliki, tetapi juga bergantung pada aspek sumber daya manusia. Di era sekarang dimana persaingan semakin tinggi, karyawan dituntut untuk melakukan pekerjaannya dengan sempurna. Kinerja baik atau buruk seorang karyawan tergantung pada seberapa puas orang tersebut dengan pekerjaannya. Seorang karyawan mampu menunjukkan kinerja yang baik bila ia merasa puas dengan pekerjaannya. Tuntutan tugas yang ada di suatu perusahaan menjadi salah satu penyebab stres pada karyawan karena tuntutan yang berat. Faktor yang dapat menyebabkan stres bagi karyawan antara lain beban kerja yang berlebihan, kompensasi yang tidak tepat dan rotasi kerja yang tidak sesuai dengan kemampuan karyawan, sehingga karyawan merasa tidak puas dengan apa yang diharapkannya. Tuntutan tugas yang ada di suatu perusahaan menjadi salah satu penyebab stres pada karyawan karena tuntutan yang berat. Faktor yang dapat menyebabkan stres bagi karyawan antara lain beban kerja yang berlebihan, kompensasi yang tidak tepat dan rotasi kerja yang tidak sesuai dengan kemampuan karyawan, sehingga karyawan merasa tidak puas dengan apa yang diharapkannya. Tuntutan tugas yang ada di suatu perusahaan menjadi salah satu penyebab stres pada karyawan karena tuntutan yang berat. Faktor-faktor yang dapat menyebabkan stres bagi karyawan antara lain beban kerja yang berlebihan, kompensasi yang tidak tepat dan perputaran pekerjaan yang tidak sesuai dengan kemampuan karyawan, sehingga karyawan merasa tidak puas dengan apa yang diharapkannya. Munandar (2014) mengartikan beban kerja sebagai suatu kondisi pekerjaan disertai uraian yang harus diselesaikan dalam waktu tertentu. Tidak hanya beban kerja yang menjadi pertimbangan dalam sebuah perusahaan, tetapi kompensasi juga harus diberikan sesuai dengan standar dan prosedur. Dalam hal ini diharapkan akan terjadi hubungan yang saling menguntungkan antara karyawan dengan pemilik perusahaan sehingga dapat mendorong semangat kerja karyawan karena kompensasi ini adalah semua pendapatan berupa uang, barang maupun yang diterima secara tidak langsung oleh karyawan sebagai imbalan atau jasa yang diberikan. kepada perusahaan. Hasibuan (2014: 118). Jika rotasi kerja dilakukan sesuai prosedur, diharapkan rotasi kerja dapat mengurangi kebosanan karyawan. Selain itu, rotasi pekerjaan diharapkan mampu meningkatkan kemampuan dan keterampilan karyawan. 
Rotasi pekerjaan juga dapat membantu karyawan memahami dengan baik tentang pekerjaan mereka yang memberikan kontribusi bagi perusahaan. Robbins dan Judge (2008: 272) mengemukakan bahwa "rotasi kerja secara tidak langsung menguntungkan organisasi pegawai yang mempunyai ketrampilan untuk memberi manajemen lebih, keluwesan dalam merencanakan pekerjaan, menyesuaikan diri dengan perubahan dan mengisi lowongan. Sehingga dengan adanya rotasi kerja maka akan dapat meningkatkan kinerja karyawan. Sesuai dengan visi menjadi bank daerah terpercaya di Indonesia, memahami kebutuhan nasabah, memberikan solusi keuangan yang tepat, membangun kemitraan yang saling menguntungkan dan berkelanjutan. PT. Bank Sulawesi Tengah Cabang Luwuk Banggai terus berupaya mengembangkan dan meningkatkan kinerja pegawai yang tidak lepas dari dukungan sumber daya manusia yang berkualitas.

\section{Tabel 1.2}

\section{Jumlah Pelanggan Sulteng Luwuk Banggai 2020}

\begin{tabular}{|l|l|l|l|l|l|}
\hline Jumlah pelanggan & 2016 & 2017 & 2018 & 2019 & 2020 \\
\hline Kredit & 1.562 & 1.725 & 1.850 & 1.922 & 2.607 \\
\hline Tabungan & 11.234 & 12.344 & 13.688 & 18.844 & 22.625 \\
\hline Giro & 3.051 & 3.251 & 3.354 & 3.735 & 3.918 \\
\hline Menyetorkan & 135 & 149 & 153 & 146 & 125 \\
\hline
\end{tabular}

Sumber: PT. Bank Sulawesi Tengah, Cabang Luwuk Banggai 2020

Berdasarkan tabel di atas, dapat diketahui bahwa jumlah nasabah PT Bank Sulteng Cabang Luwuk Banggai terus meningkat, baik dari segi kredit, tabungan, giro maupun deposito. Artinya beban kerja yang dialami karyawan juga akan meningkat. Berdasarkan observasi dan wawancara yang dilakukan di PT. Bank Sulteng Cabang Luwuk Banggai dengan beberapa pegawai terkait mengenai judul penelitian. Dikatakannya beban kerja yang dialami karyawan cukup berat, dengan bertambahnya pelanggan, mereka juga melakukan banyak beban kerja terutama di bagian teller dan CS. Namun, mereka hanya memiliki karyawan yang terbatas. Banyak karyawan yang mengeluhkan tuntutan pekerjaan yang tinggi, tenggat waktu tugas yang sempit dan jam kerja yang panjang yang membuat mereka bekerja lembur. Hal seperti ini sering terjadi dan membuat para karyawan pusing, bosan dan bingung sehingga karyawan mengalami stres kerja. Beban kerja yang terlalu berat dan membuat stres merupakan dua hal yang mempengaruhi kepuasan kerja. Jika karyawan merasa tidak puas dengan pekerjaannya, aktivitas perusahaan akan terganggu. Dengan keterbatasan jumlah karyawan, selain beban kerja yang berdampak pada kepuasan kerja, kompensasi yang diterima karyawan tidak sebanding dengan kontribusi yang mereka berikan kepada perusahaan. Pembagian kompensasi kepada karyawan berbeda-beda menurut divisi / divisi masing-masing. Kompensasi sangat penting bagi karyawan karena ukuran atau besarnya itu merupakan cerminan atau tolak ukur dari nilai kerja karyawan itu sendiri. Kompensasi mampu mempengaruhi kepuasan kerja karyawan. Semakin besar kompensasi yang diterima maka semakin baik pula kepuasan kerja yang dimiliki. Berkaitan dengan rotasi pekerjaan. Rotasi pekerjaan didasarkan pada prinsip The Right Man on The Right Job, artinya rotasi pekerjaan dilakukan untuk menempatkan karyawan pada posisi yang tepat, rotasi pekerjaan dilakukan 
berdasarkan prestasi kerja, pengalaman dan tingkat kebutuhan karyawan. Namun berbeda bagi karyawan PT Bank Sulteng Cabang Luwuk Banggai perputaran pekerjaan tersebut tidak sesuai prosedur, sehingga kepuasan kerja karyawan belum optimal. Beberapa karyawan di PT Bank Sulteng Luwuk Cabang Banggai, khususnya di Teller, CS frontliner dan divisi marketing. Berbeda dengan karyawan PT Bank Sulteng Cabang Luwuk Banggai rotasi pekerjaan tidak sesuai prosedur, sehingga kepuasan kerja karyawan belum optimal. Beberapa karyawan di PT Bank Sulteng Luwuk Cabang Banggai, khususnya di Teller, CS frontliner dan divisi marketing. Berbeda dengan karyawan PT Bank Sulteng Cabang Luwuk Banggai rotasi pekerjaan tidak sesuai prosedur, sehingga kepuasan kerja karyawan belum optimal. Beberapa karyawan di PT Bank Sulteng Luwuk Cabang Banggai khususnya di bagian Teller, CS frontliner dan marketing.

Berdasarkan uraian di atas maka dapat diajukan penelitian dengan judul: "Pengaruh Beban Kerja, Kompensasi dan Rotasi Kerja terhadap Kepuasan Kerja Melalui Stres Kerja”. (Studi Kasus di PT. Bank Central Sulawesi, Cabang Luwuk Banggai).

\subsection{Formulasi masalah}

1. Apakah Ada Pengaruh Beban Kerja terhadap Stres Kerja pada PT. Bank Sulteng, Cabang Luwuk Banggai?

2. Apakah ada pengaruh kompensasi terhadap stres kerja pada PT. Bank Sulteng, Cabang Luwuk Banggai?

3. Apakah ada pengaruh rotasi kerja terhadap stres kerja pada PT. Bank Sulteng, Cabang Luwuk Banggai?

4. Apakah ada pengaruh Beban Kerja terhadap Kepuasan Kerja pada PT. Bank Sulteng, Cabang Luwuk Banggai? 5. Apakah ada pengaruh Kompensasi terhadap Kepuasan Kerja pada PT. Bank Sulteng, Cabang Luwuk Banggai? 6. Apakah Rotasi Kerja berpengaruh terhadap Kepuasan Kerja pada PT.Bank Sulawesi Tengah Cabang Luwuk Banggai?

7. Apakah ada pengaruh stres kerja terhadap kepuasan kerja karyawan pada PT. Bank Sulteng, Cabang Luwuk Banggai?

\section{METODE PENELITIAN}

Penelitian ini menggunakan metode penelitian kuantitatif yang menekankan pada analisis data numerik (bilangan) yang diolah dengan metode statistik. Penelitian kuantitatif bekerja dengan angka, yang datanya berupa angka (skor atau skor, set, atau frekuensi), yang dianalisis menggunakan statistik untuk menjawab pertanyaan atau hipotesis penelitian tertentu dan memprediksi variabel lain. Dengan kata lain penelitian ini merupakan penelitian asosiatif yang bertujuan untuk mengetahui pengaruh atau hubungan antara dua variabel atau lebih. Penelitian ini dapat membangun teori yang berfungsi untuk menjelaskan, memprediksi dan mengontrol suatu gejala dan dapat dilakukan untuk menguji hipotesis dengan statistik inferensial.

2.1 Teknik Pengumpulan Data

Ada dua metode pengumpulan data yang digunakan dalam penelitian ini dimana semua data yang dibutuhkan dikumpulkan 
Sebuah. Penelitian lapangan (field research method) yaitu dengan menyebarkan kuesioner kepada seluruh responden yang menjadi objek penelitian.

b. Pengumpulan data juga dilakukan dengan metode studi pustaka yaitu pengumpulan data dengan melakukan studi studi terhadap buku, literatur, catatan, dan laporan yang berkaitan dengan masalah yang sedang dipecahkan.

Menurut Sugiyono (2014) populasi merupakan wilayah generalisasi yang terdiri dari objek / subjek yang mempunyai kualitas dan karakteristik tertentu yang ditentukan oleh peneliti untuk dipelajari dan diambil kesimpulannya. Populasi dalam penelitian ini adalah seluruh karyawan PT. Bank Sulteng Cabang Luwuk Banggai sebanyak 34 responden. Seluruh populasi digunakan sebagai responden (sensus). Sensus adalah cara mengumpulkan data dari suatu populasi dengan mengambil semua anggota populasi itu untuk data.

\section{HASIL DAN PEMBAHASAN}

\section{Uji validitas}

Sugiyono (2010), hasil penelitian dikatakan valid apabila terdapat kesamaan antara data yang dikumpulkan dengan data aktual yang terjadi pada objek penelitian. Valid atau tidaknya suatu instrumen dapat ditentukan dengan membandingkan indeks korelasi momen pearson dengan taraf signifikan 5\%. Jika signifikansi hasil korelasi lebih kecil dari 0,05 (5\%) maka dinyatakan valid dan sebaliknya dinyatakan tidak valid.

\section{Tabel 3.}

\section{Hasil Instrumen Penelitian Uji validitas}

\begin{tabular}{|l|l|l|l|l|l|}
\hline Variabel & Barang & R-hitung & r-tabel & Sig & Keterangan \\
\hline & XI.1 & 0,530 & & 0,001 & SAH \\
& XI.2 & 0,611 & & 0,000 & SAH \\
& XI.3 & 0,422 & 0,3494 & 0,013 & SAH \\
Beban Kerja & X1.4 & 0,394 & & 0,021 & SAH \\
(XI) & X1.5 & 0,586 & & 0,000 & SAH \\
& X1.6 & 0,594 & & 0,000 & SAH \\
& XI.7 & 0,403 & & 0,018 & SAH \\
& XI.8 & 0,464 & & 0,006 & SAH \\
& XI.9 & 0,601 & & 0,000 & SAH \\
& XI.10 & 0,383 & & 0,025 & SAH \\
\hline & X2.1 & 0,487 & & 0,003 & SAH \\
& X2.2 & 0,590 & & 0,000 & SAH \\
& X2.3 & 0,539 & 0,001 & SAH \\
& X2.4 & 0,678 & & 0,000 & SAH \\
Kompensasi & X2.5 & 0,743 & & 0,000 & SAH \\
& X2.6 & 0,707 & & 0,000 & SAH \\
& X2.7 & 0,437 & & 0,010 & SAH \\
& X2.8 & 0,362 & & 0,036 & SAH \\
& X2.9 & 0,613 & & 0,000 & SAH \\
& X2.10 & 0,777 & & 0,000 & SAH \\
\hline & X3.1 & 0,422 & & 0,013 & SAH \\
& X3.2 & 0,436 & & 0,010 & SAH \\
& X3.3 & 0,548 & & 0,001 & SAH \\
& X3.4 & 0,705 & & 0,001 & SAH \\
& X3.5 & 0,422 & 0,3494 & 0,013 & SAH \\
& X3.6 & 0,578 & & 0,000 & SAH \\
& X3.7 & 0,603 & & 0,000 & SAH \\
\hline \multirow{5}{*}{ Rotasi Kerja } & & & & \\
\hline
\end{tabular}




\begin{tabular}{|l|l|l|l|l|l|}
\hline & X3.8 & 0,491 & & 0,003 & SAH \\
& X3.9 & 0,475 & & 0,005 & SAH \\
& X3.10 & 0,445 & 0,008 & SAH \\
\hline & Y1.1 & 0,720 & & 0,000 & SAH \\
& Y1.2 & 0,570 & & 0,000 & SAH \\
& Y1.3 & 0,602 & 0,000 & SAH \\
& Y1.4 & 0,365 & 0,3494 & 0,034 & SAH \\
Kepuasan & Y1.5 & 0,459 & & 0,006 & SAH \\
(YI) & Y1.6 & 0,562 & & 0,001 & SAH \\
& Y1.7 & 0,745 & & 0,000 & SAH \\
& Y1.8 & 0,644 & & SAH \\
& Y1.9 & 0,736 & & 0,000 & SAH \\
& Y1.10 & 0,362 & & 0,035 & SAH \\
\hline & Y2.1 & 0,350 & & 0,041 & SAH \\
& Y2.2 & 0,428 & 0,020 & SAH \\
& Y2.3 & 0,397 & SAH \\
& Y2.4 & 0,364 & 0,034 & SAH \\
Stres Kerja & Y2.5 & 0,433 & 0,010 & SAH \\
& Y2.6 & 0,562 & & 0,001 & SAH \\
& Y2.7 & 0,530 & & 0,001 & SAH \\
& Y2.8 & 0,502 & & 0,002 & SAH \\
& Y2.9 & 0,491 & & 0,003 & SAH \\
& Y2.10 & 0,712 & & 0,000 & SAH \\
\hline
\end{tabular}

Sumber: data primer (diolah), februari 2020

Dari hasil uji validitas pada tabel di atas dapat diketahui bahwa semua item valid karena mempunyai nilai signifikansi dibawah 0,05 dan nilai $r$ hitung lebih besar dari nilai $r$ tabel.

\section{Tes kepercayaan}

Arikunto 2010, suatu instrumen dikatakan reliabel (reliabel) jika memiliki koefisien reliabilitas 0,6 atau lebih. Koefisien reliabilitas diperoleh dengan menggunakan rumus Alpha Cronbach. Jika kelalaian kurang dari 0,6 maka dinyatakan tidak dapat diandalkan dan sebaliknya.

\section{Tabel 3. Hasil Uji Reliabilitas Instrumen Penelitian}

\begin{tabular}{|l|l|l|}
\hline Variabel & Alpha Cronbach & Keterangan \\
\hline beban kerja (XI) & 0,740 & Reliabel \\
\hline kompensasi (X2) & 0,758 & Reliabel \\
\hline $\begin{array}{l}\text { rotasi pekerjaan } \\
(\mathrm{X} 3)\end{array}$ & 0,769 & Reliabel \\
\hline kepuasan kerja (YI) & 0,741 & Reliabel \\
\hline Stres kerja (Y2) & 0,744 & Reliabel \\
\hline
\end{tabular}

Sumber: data primer (diolah), februari 2020

Dari hasil uji reliabilitas pada tabel di atas terlihat bahwa semua variabel memiliki nilai Cronbach Alpha diatas 0,6. Jadi, semua item variabel realistis.

\section{uji analisis jalur}

Teknik analisis data adalah teknik analisis jalur. Metode ini digunakan karena dapat menguji hipotesis satu sampai sembilan variabel. Dalam analisis ini dapat diketahui bagaimana variabel independen yaitu beban kerja (X1), kompensasi (X2), rotasi kerja (X3), berpengaruh terhadap variabel dependen kepuasan kerja karyawan (Y2) dengan stres kerja (Y1) sebagai variabel intervening. Dari hasil analisis jalur 


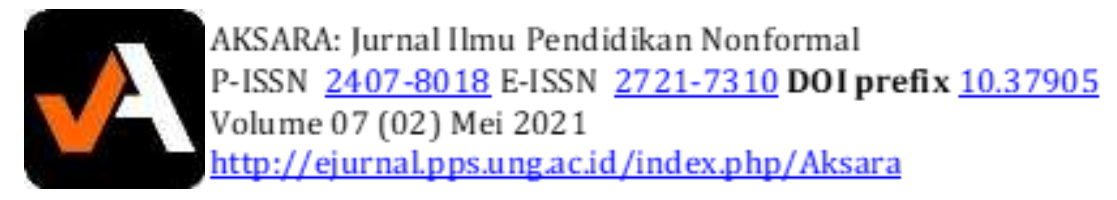

dengan menggunakan SPSS 22.0, maka hipotesis penelitian akan dibuktikan sebagaimana dijelaskan pada Bab IV. Hasil rekap analisis jalur adalah sebagai berikut:

\section{Uji Analisis Jalur Sub Struktural 1}

\section{Tabel 4. Meja}

Sub Struktur ANOVA 1

ANOVAa

\begin{tabular}{|ll|l|l|l|l|l|}
\hline Model & & Jumlah Kotak & Df & Mean Square & F & Sig. \\
\hline 1 & Regresi & 420.369 & 3 & 140.123 & 26.329 & $.000 \mathrm{~b}$ \\
& Sisa & 159.661 & 30 & 5.322 & & \\
& Total & 580.029 & 33 & & & \\
\hline
\end{tabular}

Sebuah. Variabel Dependen: stres kerja

b. Predictors: (Constant),Rotasi Kerja, Beban Kerja, Kompensasi

Sumber: data primer (diolah), februari

Nilai Probabilitas / Signifikansi menunjukkan nilai $0,000<0,05$. Hasil diatas memberikan kesimpulan bahwa terdapat pengaruh secara bersama-sama (simultan) variabel Beban Kerja, Kompensasi dan Rotasi Kerja terhadap stres kerja. Dengan demikian substruktur model 1 dapat disimpulkan layak dan dapat dilanjutkan untuk analisis lebih lanjut.

Tabel 5

Model Summary Path Analysis Sub Struktur 1

Ringkasan Model b

\begin{tabular}{|c|c|c|c|c|c|c|c|c|c|}
\hline \multirow[b]{2}{*}{ Model } & \multirow[b]{2}{*}{$\mathrm{R}$} & \multirow[b]{2}{*}{ R Square } & \multirow[b]{2}{*}{$\begin{array}{l}\mathrm{R} \text { Square } \\
\text { yang } \\
\text { disesuaikan }\end{array}$} & \multirow[b]{2}{*}{$\begin{array}{l}\text { Std. Kesalahan } \\
\text { Perkiraan }\end{array}$} & \multicolumn{5}{|c|}{ Ubah Statistik } \\
\hline & & & & & $\begin{array}{l}\mathrm{R} \text { Square } \\
\text { Change }\end{array}$ & $\begin{array}{l}\text { F } \\
\text { Perubah } \\
\text { an } \\
\end{array}$ & df1 & df 2 & $\begin{array}{l}\text { Sig. F } \\
\text { Perubahan }\end{array}$ \\
\hline 1 & $0,851 \mathrm{a}$ & 0,725 & 0,697 & 2.30695 & 0,725 & 26.329 & 3 & 30 & .000 \\
\hline
\end{tabular}

a. Predictors: (Constant), Rotasi Kerja, Beban Kerja, Kompensasi

Sumber: data primer (diolah), februari

b. Variabel Dependen: Stres Kerja

Pengujian ini dapat dilihat pada tabel Ringkasan Model di atas pada nilai R square (R2). Jumlah adalah 0,725. Angka tersebut disebut juga koefisien determinasi (KD) yang menjelaskan gabungan ( kontribusi variabel Beban Kerja (X1), kompensasi (X2) dan rotasi kerja (X3) terhadap stres kerja (Y 0,725 atau $\mathrm{KD}=\mathrm{R} 2 \times 100 \%=0,725 \times 100 \%=72,5 \%$. Sedangkan sisanya $27,5 \%$, angka terseb besarnya faktor lain di luar variabel beban kerja, kompensasi dan rotasi kerja terhadap stres kerja.

Tabel 6

Analisis jalur koefisien Sub Struktur 1

Koefisien a

\begin{tabular}{|c|c|c|c|c|c|c|c|c|}
\hline \multirow{2}{*}{\multicolumn{2}{|c|}{ Model }} & \multicolumn{2}{|c|}{ Koefisien Tidak Standar } & \multirow{2}{*}{$\begin{array}{l}\text { Koefisien Standar } \\
\text { Beta }\end{array}$} & \multirow[b]{2}{*}{$\mathrm{t}$} & \multirow[b]{2}{*}{ Sig. } & \multicolumn{2}{|c|}{ Statistik Kolinearitas } \\
\hline & & B & Std. Kesalahan & & & & Toleransi & VIF \\
\hline \multirow[t]{4}{*}{1} & (Konstan) & 0,782 & 4.460 & & 0,175 & 0,862 & & \\
\hline & Beban kerja & 0,404 & .135 & .362 & 2.982 & 0,006 & 0,622 & 1.608 \\
\hline & Kompensasi & .252 & .106 & 0,290 & -2.384 & 0,024 & 0,620 & 1.614 \\
\hline & $\begin{array}{l}\text { Rotasi } \\
\text { pekerjaan }\end{array}$ & 0,334 & 0,120 & 0,360 & 2.783 & 0,009 & 0,547 & 1.828 \\
\hline
\end{tabular}

Sebuah. Variabel Dependen: Stres kerja

Sumber: data primer (diolah), februari 
Melihat nilai signifikansi (sig) dimana pengaruhnya signifikan jika nilai signifikansi lebih kecil dari 0,05 $(<0,05)$.

\section{Uji Analisis Jalur Sub Struktural 2}

Tabel 7

Tabel ANOVA Sub Struktur 2

ANOVAa

\begin{tabular}{|ll|l|l|l|l|l|}
\hline Model & & Jumlah Kotak & Df & Mean Square & F & Sig. \\
\hline 1 & Regresi & 348.007 & 4 & 87.002 & 49.737 & $.000 \mathrm{~b}$ \\
& Sisa & 50,728 & 29 & 1.749 & & \\
& Total & 398.735 & 33 & & & \\
\hline
\end{tabular}

Sebuah. Variabel Terikat: jkepuasan kerja

b. Predictors: (Constant), kompensasi Stres pekerjaan, beban kerja, rotasi pekerjaan

Sumber: data primer (diolah), februari

Nilai Probabilitas / Signifikansi menunjukkan nilai 0,000 <0,05Hasil diatas menyimpulkan bahwa terdapat pengaruh gabungan (simultan) terhadap variabel Beban Kerja (X1) Kompensasi (X2), Rotasi Kerja (X3) dan Stres Kerja (Y1) terhadap kepuasan kerja (Y2). dapat dilanjutkan untuk analisis lebih lanjut.

Tabel 5.8

Tabel Model Ringkasan jalur analisis Sub Struktur 2

Ringkasan Model b

\begin{tabular}{|c|c|c|c|c|c|}
\hline Model & $\mathrm{R}$ & R Square & $\begin{array}{l}\text { R Square } \\
\text { yang } \\
\text { disesuai } \\
\text { kan }\end{array}$ & \begin{tabular}{|l} 
Std. \\
Kesalahan \\
Perkiraan
\end{tabular} & Durbin-Watson \\
\hline 1 & $0,934 \mathrm{a}$ & 0,873 & 0,855 & 1.32259 & 2.023 \\
\hline
\end{tabular}

Sebuah. Predictors: (Constant), Job stress, Compentation, Beban Kerja, Rotasi pekerjaan,

b. Variabel Tergantung: Kepuasan kerja

Sumber: data primer (diolah), februari

Pada bagian ini, analisis kontribusi pengaruh beban kerja (X1), kompensasi (X2), rotasi kerja (X3) dan stres kerja (Y1) digabungkan dengan variabel kepuasan kerja (Y2). Pengujian ini dapat dilihat pada tabel Ringkasan Model di atas pada nilai $\mathrm{R}$ square (R2). Angka R square adalah 0,873. Angka ini disebut juga koefisien determinasi (KD) yang menjelaskan gabungan (simultan) kontribusi beban kerja (X1), kompensasi (X2), rotasi kerja (X3) dan stres kerja (Y1) secara bersama-sama memberikan kontribusi terhadap kepuasan kerja (Y2) ). adalah 0,873 atau $\mathrm{KD}=\mathrm{R} 2$ $\mathrm{X} 100 \%=0,873 \times 100 \%=87,3 \%$. Sedangkan sisanya $12,7 \%$, angka tersebut berarti besarnya faktor lain di luar variabel beban kerja (X1) kompensasi (X2) rotasi kerja (X3) dan stres kerja (Y1) yang memberikan kontribusi terhadap kepuasan kerja (Y2), di luar model penelitian. 
Tabel 8

Tabel Koefisien jalur anylisis Sub Struktur 2

Koefisien a

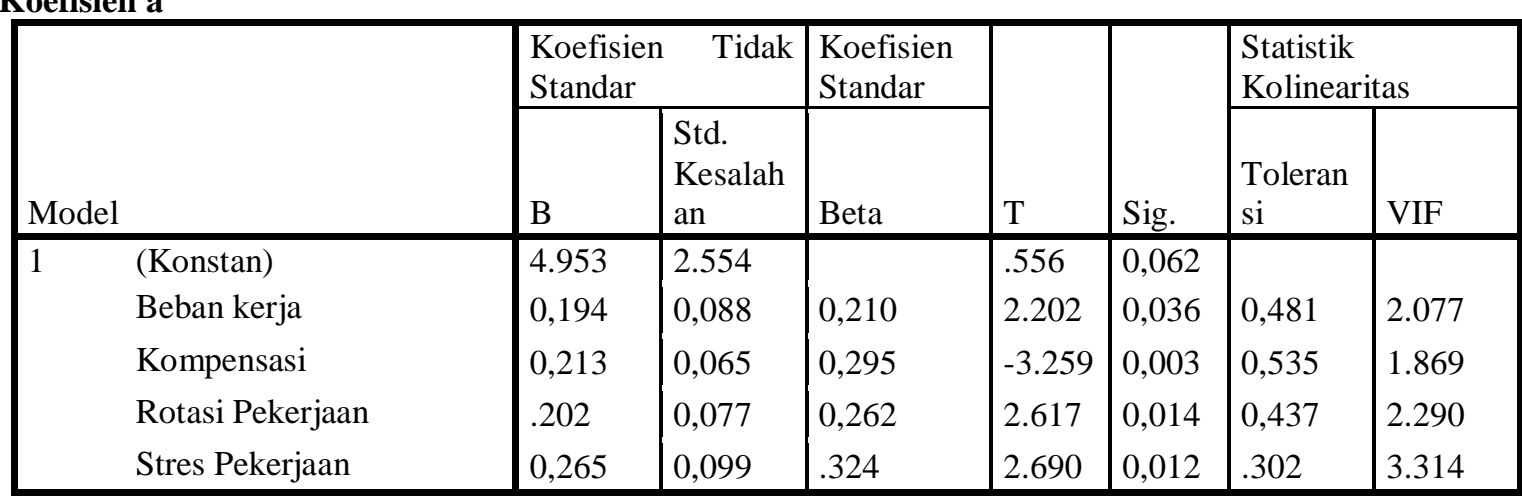

Sebuah. Variabel Tergantung: Kepuasan kerja

Sumber: data primer (diolah), februari

Melihat nilai signifikansi (sig) dimana pengaruhnya signifikan jika nilai signifikansi lebih kecil dari $0,05(<0,05)$.

Tabel 9. Proses Dekomposisi Koefisien Jalur Efek Langsung, Tidak Langsung dan Total

\begin{tabular}{|c|c|c|c|c|}
\hline \multirow[b]{2}{*}{ variabel } & \multirow[b]{2}{*}{ jalur pengaruh } & \multicolumn{2}{|c|}{ Efek Kuasal } & \multirow{2}{*}{ Total } \\
\hline & & Langsung & $\begin{array}{l}\text { tidak langsung } \\
\text { Melalui Y1 }\end{array}$ & \\
\hline \multirow[t]{2}{*}{$\mathbf{X 1}$} & X1 untuk Y1 & 0,362 & & 0,362 \\
\hline & X1 untuk Y2 & 0.210 & $\begin{array}{l}\mathbf{0 , 3 6 2} \times 0,210= \\
0,076\end{array}$ & $\begin{array}{l}0,210+0,076= \\
0,286\end{array}$ \\
\hline \multirow[t]{2}{*}{$\mathbf{X} 2$} & X2 untuk Y1 & 0,290 & & 0,290 \\
\hline & $\mathbf{X} 2$ untuk Y2 & 0.295 & $\begin{array}{l}0,290 \times 0,295= \\
0,085\end{array}$ & $\begin{array}{l}\mathbf{0 , 2 9 5}+0,085= \\
0,38\end{array}$ \\
\hline \multirow[t]{2}{*}{$\mathbf{X 3}$} & X3 untuk Y1 & $\mathbf{0 , 3 6 0}$ & & $\mathbf{0 , 3 6 0}$ \\
\hline & $\mathbf{X 3}$ untuk Y2 & 0.262 & $\begin{array}{l}0,360 \times 0,262= \\
0,094\end{array}$ & $\begin{array}{l}0,262+0,094= \\
0,356\end{array}$ \\
\hline Y1 & Y1 untuk Y2 & 0,324 & & 0,324 \\
\hline
\end{tabular}

Sumber: data primer (diolah), februari

Berdasarkan tabel di atas, hasil dekomposisi koefisien jalur pengaruh langsung, pengaruh tidak langsung dan pengaruh total dapat diartikan sebagai berikut:

\section{Pengaruh Langsung (Langsung)}

Sebuah. Beban kerja (X1) berpengaruh langsung terhadap stres kerja (Y1) sebesar 0,362 atau $36,2 \%$

b. Beban Kerja (X1) berpengaruh langsung terhadap Kepuasan Kerja (Y2) sebesar 0,210 atau $21,0 \%$ 
c. Kompensasi (X2) berpengaruh langsung terhadap stres kerja (Y1) sebesar 0,290 atau $29,0 \%$

d. Kompensasi (X2) berpengaruh langsung terhadap Kepuasan Kerja (Y2) sebesar 0,295 atau $29,5 \%$

e. Rotasi Kerja (X3) berpengaruh langsung terhadap stres kerja (Y1) sebesar 0,360 atau $36,0 \%$

f. Rotasi Pekerjaan (X3) berpengaruh langsung terhadap Kepuasan Kerja (Y2) sebesar 0,262 atau 26,2\%

g. Stres kerja (Y1) berpengaruh langsung terhadap Kepuasan Kerja (Y2) sebesar 0,265 atau $26,5 \%$

\section{Pengaruh Tidak Langsung}

Sebuah. Beban Kerja (X1) berpengaruh tidak langsung terhadap Kepuasan Kerja (Y2) melalui variabel stres kerja (Y1) sebesar 0,076 atau 7,6\%

b. Kompensasi (X2) berpengaruh tidak langsung terhadap Kepuasan Kerja (Y2) melalui variabel stres kerja (Y1) sebesar 0,085 atau 8,5\%

c. Rotasi Kerja (X3) berpengaruh tidak langsung terhadap Kepuasan Kerja (Y2) melalui variabel stres kerja (Y1) sebesar 0,094 atau 9,4\%

\section{Pengaruh Total}

Sebuah. Pengaruh total beban kerja (X1) terhadap kepuasan kerja (Y2) sebesar 0,286 atau $28,6 \%$.

b. Pengaruh kompensasi total (X2) terhadap kepuasan kerja (Y2) sebesar 0,360 atau $0,36,0 \%$

c. Pengaruh total rotasi kerja (X3) terhadap kepuasan kerja (Y2) sebesar 0,356 atau $35,6 \%$.

1. Pengaruh beban kerja terhadap stres kerja karyawan pada PT Bank Sulteng Luwuk Cabang Banggai Dari hasil perhitungan menggunakan SPSS 22.0, nilai probabilitas lebih signifikan dari alpha (5\%) atau 0,006>0,05. Dengan demikian, dapat disimpulkan bahwa beban kerja berpengaruh signifikan terhadap stres kerja karyawan pada PT Bank Sulteng Cabang Luwuk Bangga. Hipotesis yang menyatakan bahwa "beban kerja berpengaruh signifikan terhadap stres kerja karyawan pada PT Bank Sulteng Luwuk Cabang Banggai” terbukti signifikan.

2. Pengaruh kompensasi terhadap stres kerja karyawan pada PT Bank Sulteng Luwuk Cabang Banggai Dari hasil perhitungan menggunakan SPSS 22.0, nilai probabilitas lebih signifikan dari alpha (5\%) atau 0,006>0,05. Dengan demikian, dapat disimpulkan bahwa kompensasi berpengaruh signifikan terhadap stres kerja karyawan pada PT Bank Sulteng Cabang Kebanggaan Luwuk. Hipotesis yang menyatakan bahwa "Kompensasi berpengaruh signifikan terhadap stres kerja karyawan pada PT Bank Sulteng Luwuk Cabang Banggai” terbukti signifikan.

3. Pengaruh rotasi kerja terhadap stres kerja karyawan pada PT Bank Sulteng Luwuk Cabang Banggai Dari hasil perhitungan menggunakan SPSS 22.0, nilai probabilitas lebih signifikan dari alpha (5\%) atau 0,024>0,05. Dengan demikian dapat disimpulkan bahwa rotasi kerja berpengaruh signifikan terhadap stres kerja karyawan pada PT Bank Sulteng Cabang Kebanggaan 


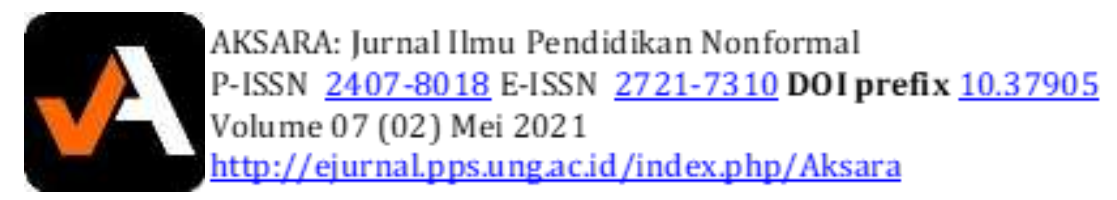

Luwuk. Hipotesis yang menyatakan bahwa "rotasi kerja berpengaruh signifikan terhadap stres kerja karyawan pada PT Bank Sulteng Luwuk Cabang Banggai” terbukti signifikan.

4. Pengaruh beban kerja pada karyawan terhadap kepuasan kerjaPada PT Bank Sulteng Luwuk Cabang Banggai Dari hasil perhitungan menggunakan SPSS 22.0 diperoleh nilai probabilitas yang lebih signifikan dari alpha $(5 \%)$ atau 0,009> 0,05. Dengan demikian, dapat disimpulkan bahwa beban kerja berpengaruh signifikan terhadap kepuasan kerja karyawan pada PT Bank Sulteng Cabang Kebanggaan Luwuk. Hipotesis yang menyatakan bahwa "beban kerja berpengaruh signifikan terhadap kepuasan kerja karyawan pada PT Bank Sulteng Luwuk Cabang Banggai” terbukti signifikan.

5. Pengaruh kompensasi pada karyawan terhadap kepuasan kerjaPada PT Bank Sulteng Luwuk Cabang Banggai Dari hasil perhitungan menggunakan SPSS 22.0 diperoleh nilai probabilitas yang lebih signifikan dari alpha $(5 \%)$ atau 0.036> 0.05. Dengan demikian, dapat disimpulkan bahwa kompensasi berpengaruh signifikan terhadap kepuasan kerja karyawan pada PT Bank Sulteng Cabang Kebanggaan Luwuk. Hipotesis yang menyatakan bahwa "kompensasi berpengaruh signifikan terhadap kepuasan kerja karyawan pada PT Bank Sulteng Luwuk Cabang Banggai" terbukti signifikan.

6. Pengaruh rotasi kerja terhadap karyawan terhadap kepuasan kerjaPada PT Bank Sulteng Luwuk Cabang Banggai Dari hasil perhitungan menggunakan SPSS 22.0 diperoleh nilai probabilitas yang lebih signifikan dari alpha $(5 \%)$ atau 0,003> 0,05. Dengan demikian, dapat disimpulkan bahwa kompensasi berpengaruh signifikan terhadap kepuasan kerja karyawan pada PT Bank Sulteng Cabang Kebanggaan Luwuk. Hipotesis yang menyatakan bahwa "rotasi kerja berpengaruh signifikan terhadap kepuasan kerja karyawan pada PT Bank Sulteng Luwuk Cabang Banggai" terbukti signifikan.

7. Pengaruh stres kerja pada karyawan terhadap kepuasan kerjaPada PT Bank Sulteng Luwuk Cabang Banggai Dari hasil perhitungan menggunakan SPSS 22.0 diperoleh nilai probabilitas yang lebih signifikan dari alpha $(5 \%)$ atau 0,014> 0,05. Dengan demikian, dapat disimpulkan bahwa stres kerja berpengaruh signifikan terhadap kepuasan kerja karyawan pada PT Bank Sulteng Cabang Kebanggaan Luwuk. Hipotesis yang menyatakan bahwa "stres kerja berpengaruh signifikan terhadap kepuasan kerja karyawan pada PT Bank Sulteng Luwuk Cabang Banggai” terbukti signifikan.

\section{PENUTUP}

Dari hasil penelitian dan pembahasan pada bab sebelumnya dapat disimpulkan sebagai berikut:

1. Beban kerja berpengaruh signifikan terhadap stres kerja karyawan pada PT. Bank Sulteng, Cabang Luwuk Banggai. 2. Kompensasi berpengaruh signifikan terhadap stres kerja karyawan pada PT. Bank Sulteng, Cabang Luwuk Banggai.

3. Rotasi kerja karyawan berpengaruh signifikan terhadap stres kerja karyawan pada PT. Bank Sulteng, Cabang Luwuk Banggai.

4. Beban kerja berpengaruh signifikan terhadap kepuasan kerja pada PT. Bank Sulteng, Cabang Luwuk Banggai. 
5. Kompensasi berpengaruh signifikan terhadap kepuasan kerja pada PT. Bank Sulteng, Cabang Luwuk Banggai.

6. Rotasi Kerja Karyawan berpengaruh signifikan terhadap kepuasan kerja pada PT. Bank Sulteng, Cabang Luwuk Banggai.

7. Stres kerja berpengaruh signifikan terhadap kepuasan kerja karyawan pada PT. Bank Sulteng, Cabang Luwuk Banggai.

\section{DAFTAR PUSTAKA}

Arikunto, S. 2010. Prosedur Penelitian, Pendekatan Praktis. Jakarta: Rineka Cipta. Andi, Rina 2018 Pengaruh Kompensasi dan Work Life Balance terhadap Kepuasan Kerja yang Dimediasi oleh Stres Kerja. Jurnal Internasional Penemuan Bisnis dan Manajemen (IJBMI) ISSN (Online): 2319 -8028, ISSN (Cetak): 2319 801Xwww.ijbmi.org || Volume 7 Edisi 5 Ver. IV || Mungkin. 2018 || J - 79-87

Anisa 2018. Pengaruh Kompensasi, Stres Kerja, dan Motivasi terhadap Kepuasan Kerja (Dinas Kesehatan Kabupaten Karawang). Skripsi, Universitas Jenderal Soedirman.

Anggraini, Rati. 2019. Pengaruh Motivasi dan Beban Kerja terhadap Kepuasan Kerja Karyawan pada PT. Sumber Tirta Anugrah Rezeki Pekanbaru. Skripsi, Fakultas Ekonomi dan Ilmu Sosial Universitas Islam Negeri Sultan Syraif Kasim Riau

Hasibuan, SP. (2014). Manajemen Sumber Daya Manusia, Percetakan Keempat Belas, Jakarta, Penerbit: Bumi Aksara.

Khaidir. (2013) "Pengaruh Kompensasi dan Lingkungan Kerja terhadap Kepuasan Kerja Karyawan PT. Karya Mitra Muda". Jurnal Manajemen 2.01

Mangkuprawira, Tb. Sjafri, 2009, Cakrawala Bisnis, Manajemen dan Sumber Daya Manusia, Bogor: PT. Gramedia

Melati,, Ida (2015). Pengaruh beban kerja terhadap kepuasan kerja dengan variabel mediasi pekerjaan. E-Jurnal Manajemen, [Sl], v. 4, n. 5, Mei 2015. ISSN 23028912. Tersedia di: <https://ojs.unud.ac.id/index.php/Mana Manajemen / article / view / 11574>.

Munandar, S. (2014). Psikologi Industri dan Organisasi. Penerbit, Universitas Indonesia (UI-Press). Jakarta.

Puspita dan Bernedet Ratih, 2006. Pengaruh Stres Kerja terhadap Kepuasan Kerja Karyawan PT Sharp Electronics Indonesia.

Robbins SP, dan Hakim. 2008. Buku Perilaku Organisasi 2, Jakarta: Salemba Empat halaman 272

Sormin, dkk. 2017. Pengaruh Stres Kerja terhadap Kepuasan Kerja dan Dampaknya terhadap Kinerja Karyawan pada Karyawan di Pt Panin Bank Banjarmasin. Jurnal Wawasan Manajemen. Vol. 5, No. 1, h: 63-72.

Sunyoto, Danang, 2012. Manajemen Sumber Daya Manusia. Jakarta: PT Buku Seru.http://repository.upi.edu/17628/4/S_MBS_1001311_Bibliografi

Sugiyono. (2014). Metode Penelitian Bisnis (Pendekatan Kuantitatif, Kualitatif, dan R\&D). Alfabeta: Bandung.

Sugiyono. 2010. Metode Penelitian Pendidikan dengan Pendekatan Kuantitatif, Kualitatif, dan R\&D. Bandung: Alphabeta 
Tarmizi \& Suryani (2017). Pengaruh Stres kerja terhadap kepuasan dan komitmen karyawan: Studi pada PT. FEI. Bawal Widya Riset Manajemen dan Bisnis (JRMB) Fakultas Ekonomi UNIAT, 2 (3), 315-322

Tania, M., \& Hidayati, E. (2019). Realisasi rotasi kerja ke tingkat stree perawat. $\begin{array}{llll}\text { Jurnal Keperawatan, } & 11 & \text { 73-78. }\end{array}$ https://doi.org/https://doi.org/10.32583/keperawatan.v11i1.46

Wen-hsein Ho, Ching S Chang, Ying -Ling shih dan Rong_Da Liang. 2009. Pengaruh rotasi pekerjaan dan tekanan peran perawat terhadap kepuasan kerja dan komitmen organisasi.

Setiawan, R., Pio, L., Cavaliere, L., Sankaran, D., Rani, K., Yapanto, LM, Laskar, NH, Raisal, I., Christabel, GJA, Setiawan, R., Petra, Inggris, Airlangga, U., Pio, L., Cavaliere, L., \& Foggia, U. (nd). Akses ke Layanan Keuangan dan Pemberdayaan Perempuan, melalui kelayakan Keuangan Mikro. 1, 841-859.

Yo, Putu Melati Purbaningrat \& Surya, Ida Bagus Ketut. 2015. Pengaruh Beban Kerja terhadap Kepuasan Kerja dengan Stres Kerja sebagai Variabel Mediasi. E-Journal of Management Universitas Udayana, 4 (5), hal. 1149-1165. 
632 AKSARA: Jurnal Ilmu Pendidikan Nonformal 